Contents list available at IJRED website

Int. Journal of Renewable Energy Development (IJRED)

Journal homepage: http://ejournal.undip.ac.id/index.php/ijred

\title{
Influence of the Determination Methods of K and C Parameters on the Ability of Weibull Distribution to Suitably Estimate Wind Potential and Electric Energy
}

\author{
Ruben M. Mouangue ${ }^{\mathrm{*}}{ }^{\text {Myrin Y. Kazet }}{ }^{\mathrm{b}}$, Alexis Kuitche ${ }^{\mathrm{b}}$ and Jean-Marie Ndjakac \\ aDepartment of Energetic Engineering, UIT, UN, PO Box 455 Ngaoundere, CAMEROON \\ ${ }^{b}$ Department of GEEA, PAI, ENSAI, University of Ngaoundere, CAMEROON \\ cDepartment of Physics, Faculty of Sciences, University of Yaounde I, CAMEROON
}

\begin{abstract}
The modeling of the wind speed distribution is of great importance for the assessment of wind energy potential and the performance of wind energy conversion system. In this paper, the choice of two determination methods of Weibull parameters shows theirs influences on the Weibull distribution performances. Because of important calm winds on the site of Ngaoundere airport, we characterize the wind potential using the approach of Weibull distribution with parameters which are determined by the modified maximum likelihood method. This approach is compared to the Weibull distribution with parameters which are determined by the maximum likelihood method and the hybrid distribution which is recommended for wind potential assessment of sites having nonzero probability of calm. Using data provided by the ASECNA Weather Service (Agency for the Safety of Air Navigation in Africa and Madagascar), we evaluate the goodness of fit of the various fitted distributions to the wind speed data using the Q - Q plots, the Pearson's coefficient of correlation, the mean wind speed, the mean square error, the energy density and its relative error. It appears from the results that the accuracy of the Weibull distribution with parameters which are deter mined by the modified maximum likelihood method is higher than others. Then, this approach is used to estimate the monthly and annual energy productions of the site of the Ngaoundere airport. The most energy contribution is made in March with 255.7 MWh. It also appears from the results that a wind turbine generator installed on this particular site could not work for at least a half of the time because of higher frequency of calm. For this kind of sites, the modified maximum likelihood method proposed by Seguro and Lambert in 2000 is one of the best methods which can be used to determinate the Weibull parameters.
\end{abstract}

Keywords: frequency of calm, Weibull parameters, wind energy, wind modeling, wind potential

Article History: Received December 12, 2013; Received in revised form May 20, 2014; Accepted June 12, 2014; Available online

How to Cite This Article: Mouangue, R.M., Kazet, M.Y., Kuitche, A. \& Ndjaka, J.M. (2014) Influence of the Determination Methods of K and C Parameters on the Ability of Weibull Distribution to Suitably Estimate Wind Potential and Electric Energy. Int. Journal of Renewable Energy Development, 3(2), 145-154.

http://dx.doi.org/10.14710/ijred.3.2.145-154

\section{Introduction}

Energy is an essential ingredient of socio-economic development and economic growth. The need for implementing new and clean energy technologies became pressing due to the awaited rarefaction of the fossil resources on which our development since nearly two centuries was built (Omer 2008; Rahman et al.
2014). In the interest of sustainable development, the implementation of renewable solutions in complement of other existing solutions is not any more to prove.

Because of pollution and greenhouse gas, the wind energy, which is a reliable and promising renewable energy, have attracted increasing attention due to their almost inexhaustible and nonpolluting characteristics (Li \& Li 2005; Omer 2008). The conversion of wind

\footnotetext{
* Corresponding author: Tel.:+ 23777461006 / + 23795833564

Email: ruben.mouangue@univ-ndere.cm / r_mouangue@yahoo.fr
} 
energy for the electrical production or pumping could thus help to solve a certain number of problems of the African populations.

Before thinking about wind turbine installation, it is necessary to have minimum information on wind characteristics such as the observed frequency distributions of wind speed, the wind energy density, the predominant direction of wind speed, and the daily and seasonal variations of wind.

The first part of this paper consists of the presentation of our research motivation and objectives and a summary description of our site of study. Secondly, we will make a detailed description of the Weibull and Hybrid wind distribution models as well as a presentation of the determination methods of $k$ and $C$ parameters including in particular the Maximum Likelihood Method and the Modified Maximum Likelihood Method. Then, we will evaluate the mean wind speed, the standard deviation and the mean square error using the different distributions described. In order to predict the provided electric energy, we approximate a VESTAS V82 power curve. The third part is a description of wind conditions data. We will present the obtained results and discuss them in our last part.

\subsection{Research motivation and objectives}

The increasingly rising interest in estimating wind power and wind energy potential at a given site highlights the importance of the statistical simulation of wind speed observations. Research and studies on wind power assessment and its applications in Ngaoundere has not yet been carried out. The realization of this research may enables professionals to identify, clearly and precisely, areas which could be suitable for the establishment of future parks of wind energy for sustainable development.

The wind speed distribution is of great importance for the wind energy potential assessment and for the performance of the wind energy conversion system. The Weibull distribution with two parameters is versatile and is commonly used for fitting the measured wind speed probability distribution (Seguro \& Lambert 2000; Kaldellis 2008; Safari \& Gasore 2010; Boudia et al. 2013; Kazet et al. 2013). A few years ago, the preferred method of calculating the Weibull parameters was a graphical technique which entailed generating the cumulative wind speed distribution, plotting it on a special Weibull graph paper, and drawing a line of best fit (Takle \& Brown 1978; Seguro \& Lambert 2000). Later, this procedure was implemented by performing a linear regression on a computer (Jamil et al. 1995). Seguro and Lambert (2000), by using sample data which did not have null speed measurements (calm), demonstrated that the maximum likelihood method is a more suitable computer-based method for estimating the Weibull parameters. The Weibull distribution with parameters which are calculated by this method showed some deficiencies for sample data of sites having calm (Salami et al. 2013). The use of Hybrid distribution has also been noted many times: Takle and Brown (1978), Salami et al. (2013). For sites having nonzero probability of calm, these authors pointed out the fact that the Weibull distribution is not suitable for the modeling of the wind speed distributions and for the wind potential assessment. They recommend the use of the hybrid distribution for these cases.

Today, there are several ways to estimate $k$ and $C$ parameters. Some of the most used are the maximum likelihood method, the least square method and the standard deviation method (Ramírez \& Carta 2005; Sathyajith 2006; Safari \& Gasore 2010; Morales et al. 2012). The processes of the calculation of $k$ and $C$ parameters being different, disparities in the results could thus influence the accuracy of a distribution in the modeling of the wind speed frequency histogram.

Time-series wind data collected at the Ngaoundere meteorological station show that the calm is very important. In this work, our purpose is to show that the Weibull distribution can also be used for sites having nonzero probability of calm, in the condition that the Weibull parameters determination method is well selected. Using data collected at a site of Ngaoundere, we evaluate the observable wind speed distribution and the wind energy density that we model by using the Weibull distribution and the hybrid distribution approaches. Finally, we provide an estimate of the electric output energy which could be produced on this site.

\subsection{Brief description of the site}

Ngaoundere is the capital of the Adamawa Region of Cameroon. It lies at the northern end of the railway to Yaounde (capital of Cameroon) and is also home to an airport. Ngaoundere is the most important town of the region and is the highest habitable zone of the country with an elevation of $1104 \mathrm{~m}$ (ASECNA 2012). The ASECNA weather service (Agency for the Safety of Air Navigation in Africa and Madagascar) is located at the airport and the geographic longitude - latitude coordinates of the wind data collection mast are $13^{\circ} 33^{\prime}$ 46.26" E and 7०21' 24.37" N.

\section{Materials and Methods}

\subsection{Weibull wind distribution (WWD) model}

The probability density function $f(v)$ indicates the fraction of time (or probability) for which the wind is at a given speed $\mathrm{v}$. It is given by equation (1).

$$
f(v)=\frac{k}{C}\left(\frac{v}{C}\right)^{k-1} \exp \left[-\left(\frac{v}{C}\right)^{k}\right]
$$


where:

- $\quad k$ is the Weibull shape parameter,

- $C$ is the scale parameter $(\mathrm{m} / \mathrm{s})$,

- $\quad \mathrm{v}$ is the wind speed $(\mathrm{m} / \mathrm{s})$,

- $\mathrm{f}(\mathrm{v})$ is the probability density function.

The cumulative distribution function $F(v)$ gives us the fraction of time (or probability) that the wind speed is equal or lower than $v$. It is the integral of the probability density function. Thus,

$F(v)=\int_{0}^{v} f(v) d v=1-\exp \left[-\left(\frac{v}{C}\right)^{k}\right]$

\subsubsection{Determination of Weibull parameters}

a) The Maximum Likelihood Method

By using this method, the shape factor $k$ and the scale factor $C$ are estimated solving the following two equations (Salami et al. 2013; Boudia et al. 2013):

$k=\left(\frac{\sum_{i=1}^{n} v_{i}^{k} \operatorname{Ln}\left(v_{i}\right)}{\sum_{i=1}^{n} v_{i}^{k}}-\frac{\sum_{i=1}^{n} \operatorname{Ln}\left(v_{i}\right)}{n}\right)^{-1}$

$C=\left(\frac{1}{n} \sum_{i=1}^{n} v_{i}^{k}\right)^{\frac{1}{k}}$

where:

- $v_{i}$ is the wind speed in time step $i$,

- $n$ is the number of nonzero wind speed data points.

Equation (3) is solved using an iterative procedure. In this work, this is performed using a Fortran 90 code and the initial guess used is $k=2$ (Seguro \& Lambert 2000). After which, equation (4) is solved explicitly.

b) The Modified Maximum Likelihood Method

According to Seguro and Lambert (2000), this method most be used when data wind speed are available in the frequency distribution format. The Weibull parameters are estimated using equation (5) and (6).

$k=\left(\frac{\sum_{i=1}^{n} v_{i}^{k} \operatorname{Ln}\left(v_{i}\right) f\left(v_{i}\right)}{\sum_{i=1}^{n} v_{i}^{k} f\left(v_{i}\right)}-\frac{\sum_{i=1}^{n} \operatorname{Ln}\left(v_{i}\right) f\left(v_{i}\right)}{F(v \geq 0)}\right)^{-1}$
$C=\left(\frac{1}{F(v \geq 0)} \sum_{i=1}^{n} v_{i}^{k} f\left(v_{i}\right)\right)^{\frac{1}{k}}$

where:

- $v_{i}$ is the wind speed central to bin $\mathrm{i}$,

- $n$ is the number of bins,

- $f\left(v_{i}\right)$ is the frequency with which the wind speed fall within bin $i$,

- $F(v \geq 0)$ is the probability that the wind speed equals or exceeds zero.

In this work, equation (5) is also solved using an iterative procedure with a Fortran 90 code. The initial guess is also $k=2$. After which, equation (6) is solved explicitly.

\subsubsection{Mean speed, standard deviation and Energy density}

a) Mean speed

The mean wind speed of a regime, following the Weibull distribution, is given by equation (7) (Sathyajith 2006; Kaldellis 2008):

$$
V_{m}=\int_{0}^{\infty} v f(v) d v=C \Gamma\left(1+\frac{1}{k}\right)
$$

Here, $\Gamma()$ is the gamma function.

\section{b) Standard deviation}

The standard deviation shows how much variation or dispersion from the average exists. A low standard deviation indicates that the data points tend to be very close to the mean. A high standard deviation indicates that the data points are spread out over a large range of values. Following the Weibull distribution, the standard deviation of the wind speed is calculated by equation (8).

$$
\sigma=C\left[\Gamma\left(1+\frac{2}{k}\right)-\Gamma^{2}\left(1+\frac{1}{k}\right)\right]^{\frac{1}{2}}
$$

\section{c) Energy density}

The total energy, contributed by all possible speeds in the wind regime, available for unit rotor area and time may be expressed as (Sathyajith 2006; Sathyajith \& Geeta 2011):

$$
E_{D}=\int_{0}^{\infty} \frac{1}{2} \rho v^{3} f(v) d v
$$

Hence, 


$$
E_{D}=\frac{1}{2} \rho C^{3} \Gamma\left(1+\frac{3}{k}\right)
$$

$\rho=1.03 \mathrm{~kg} / \mathrm{m}^{3}$ is the mean air density at the airport of Ngaoundere (ASECNA 2012).

\section{d) Relative error and mean square error}

The relative error expresses the variation, as a percentage, between the predicted value and the awaited value. The relative error (RE) on the mean energy density is calculated by the equation (11):

$$
R E=\frac{\left|E_{D D}-E_{D P}\right|}{E_{D D}} * 100
$$

where:

- $E_{D D}$ is the energy density obtained from data,

- $E_{D P}$ is the energy density predicted,

- $R E$ is the relative error (\%).

The mean square error (MSE) is one of many ways to quantify the difference between values implied by an estimator and the true values of the quantity being estimated. MSE here is calculated by the equation (12).

$$
M S E=\frac{1}{N} \sum_{i=1}^{N}\left(v_{i}-p_{i}\right)^{2}
$$

Here:

- $v_{i}$ is the actual wind speed,

- $\quad p_{i}$ his predicted value.

\subsubsection{Electric output energy}

The question of primary interest in wind power applications is of course: What power production can be expected from a given wind turbine at a given site? To answer this, it is necessary to know the power curve of the wind turbine as well as the probability density function of the wind speed at hub height. The power production by a wind turbine varies with the wind that strikes the rotor. It is common practice to use the wind speed at hub height as a reference for the power response of the wind turbine. The power produced as function of the wind speed at hub height is conventionally called the power curve. The Fig. 1 below shows the power curve of Vestas V82 wind turbine generator (Vestas Technology documentation 2005).

When the wind speed is less than the cut-in wind speed, the turbine will not be able to produce power. When the wind speed exceeds the cut-in speed, the power output increases with increasing wind speed to a maximum value, the rated power; thereafter the output is almost constant. At wind speeds higher than the cut-

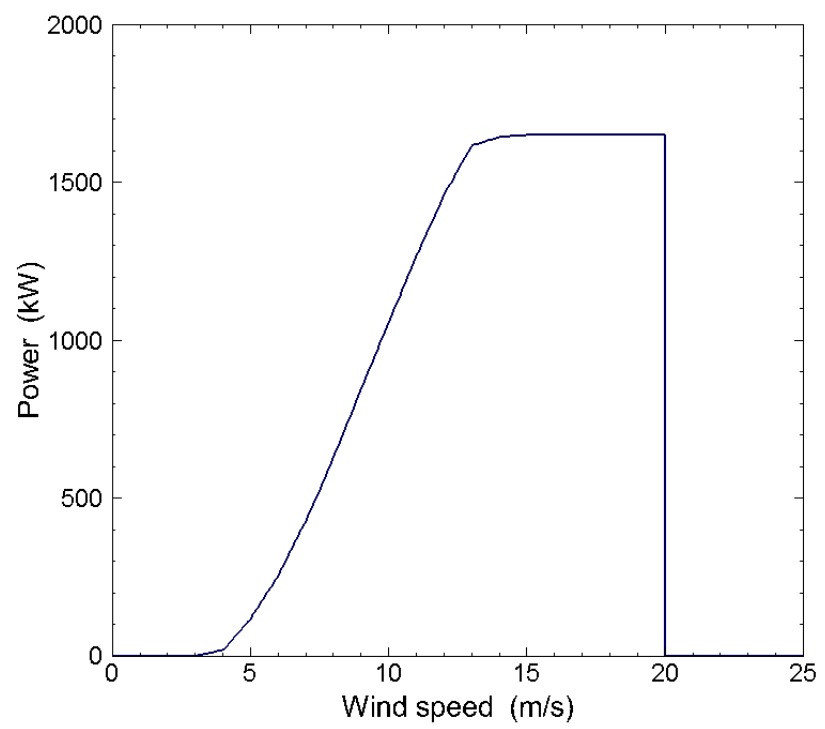

Fig. 1 Power curve of Vestas V82 wind turbine generator

out wind speed the wind turbine is stopped to prevent structural failures. The product of the power curve and the probability density function of the wind speed gives the power density curve, the integral of which is the mean power production PEL (Bataineh and Dalalah, 2013):

$P_{E L}=\int_{V_{d}}^{V_{n}} P(v) f(v) d v+P_{n} \int_{V_{n}}^{V_{a}} f(v) d v$

Actual power curves are rather smooth and can be well approximated by a piece-wise linear function with a few nodes $\left(P_{i}, v_{i}\right)$ (Troen \& Petersen 1989). It is possible to carry out an approximation which consists of assuming that the variation between two nodes of the power-wind speed curve is linear (Troen \& Petersen 1989; Carta et al. 2008). Then, given two points "i" and " $i+1$ " of the power curve, power as a function of speed can be written as Equation (14).

$P(v)=\frac{P_{i+1}-P_{i}}{v_{i+1}-v_{i}}\left(v-v_{i}\right)+P_{i}$

Hence, the annual energy production is:

$E_{E L}=P_{E L} * N_{H}$

$N_{H}$ is the time period of data collection (in hours).

\subsection{Hybrid wind distribution (HWD)}

For data sets having high probability of calm and a low value of scale parameter $\mathrm{C}$, the Weibull function is not likely to provide a good fit to the data (Takle \& Brown 1978). The problem of properly including calm periods into the distribution is reduced by defining a 
hybrid density function (Takle \& Brown 1978; Salami et al. 2013). Hence,

$$
f_{H}(v)=\left(1-F_{o}\right) \frac{k}{C}\left(\frac{v}{C}\right)^{k-1} \exp \left[-\left(\frac{v}{C}\right)^{k}\right]
$$

$F_{o}$ is the probability of observing zero wind speed. Parameters values $k$ and $C$ are determined by solving equation (3) and (4).

The corresponding cumulative distribution function is defined by (Takle \& Brown 1978),

$$
F_{H}(v)=F_{o}+\left(1-F_{o}\right)\left(1-\exp \left[-\left(\frac{v}{C}\right)^{k}\right]\right)
$$

The mean speed, standard deviation and energy density of this distribution are then respectively,

$$
\begin{aligned}
V_{m}^{H} & =C\left(1-F_{o}\right) \Gamma\left(1+\frac{1}{k}\right) \\
\sigma_{H} & =\sqrt{C^{2}\left(1-F_{o}\right) \Gamma\left(1+\frac{2}{k}\right)-V_{m}^{H 2}} \\
E_{D} & =\frac{1}{2} \rho C^{3}\left(1-F_{o}\right) \Gamma\left(1+\frac{3}{k}\right)
\end{aligned}
$$

\section{Wind condition data}

Measured wind speed data are commonly available in time-series format, in which each data point represents an average wind speed over some time period. In some instances, wind speed data may instead be available in frequency distribution format.

\subsection{Measurements}

Data used in this paper was obtained at meteorological airport station of Ngaoundere. Data were recorded every day by 30 minutes interval (Average over 10 minutes around the time of measure) at the standard height of $10 \mathrm{~m}$ above the ground.

\subsection{Vertical extrapolation}

The estimation of the wind resource at the hub height of a wind turbine is one of the primary goals of the site assessment. Because the measurement heights of meteorological towers are typically significantly lower than turbine hub height, a mathematical model is generally needed to extrapolate the measured wind resource at the lower measurement height to the hub height of the turbine. In this work, we used the Hellmann exponential law defined by equation (21), which is one of the most commonly used models (Lackner et al. 2010; Đurišić \& Mikulović 2012; Bataineh \& Dalalah 2013).

$V=V_{R}\left(\frac{H}{H_{R}}\right)^{\alpha}$

where:

- $\alpha$ is the wind shear coefficient, dependent mainly on the terrain roughness and atmospheric stability,

- $H_{R}$ is the reference height $(\mathrm{m})$,

- $\quad H$ is the height desired (m),

- $V_{R}$ is the wind speed at the reference height $(\mathrm{m} / \mathrm{s})$,

- $\quad V$ is the wind speed at the height desired $(\mathrm{m} / \mathrm{s})$.

For our site, $\alpha=0.3365$ (ASECNA 2012).

\subsection{Data processing}

To succeed in it, we used usual equations below:

- $\quad$ Mean speed

$$
\bar{v}=\frac{\sum_{i=1}^{n} v_{i} f\left(v_{i}\right)}{\sum_{i=1}^{n} f\left(v_{i}\right)}
$$

$$
\sigma=\sqrt{\frac{\sum_{i=1}^{n} f\left(v_{i}\right)\left(v_{i}-\bar{v}\right)^{2}}{\sum_{i=1}^{n} f\left(v_{i}\right)}}
$$

$$
\text { - } \quad \text { Energy density }
$$

$$
\overline{E_{D}}=\frac{1}{2} \rho \frac{\sum_{i=1}^{n} v_{i}^{3} f\left(v_{i}\right)}{\sum_{i=1}^{n} f\left(v_{i}\right)}
$$




\subsection{Picture of the site}

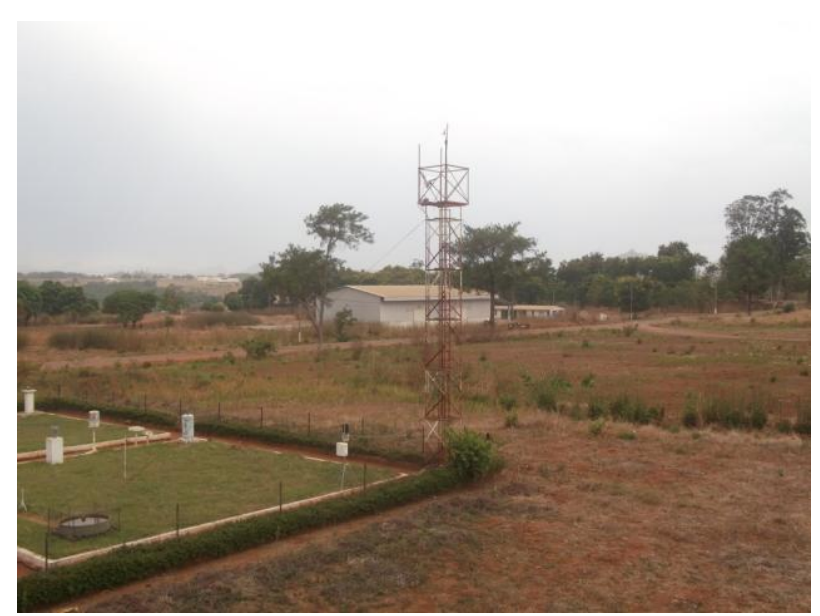

Fig. 2 Mast of the wind data collection of the Ngaoundere Airport

\section{Result and Discussion}

By using the Ngaoundere wind data, the Weibull wind distribution model is applied to two different cases:

- $\mathrm{k}$ and $\mathrm{C}$ parameters are determined by the modified maximum likelihood method (MoMaLiMe) (Seguro \& Lambert 2000).

- $\mathrm{k}$ and $\mathrm{C}$ parameters are determined by the maximum likelihood method (MaLiMe) (Seguro \& Lambert 2000; Boudia et al. 2013).

To evaluate the accuracy of our approach, the model is investigated and compared to the hybrid wind distribution model (Takle \& Brown 1978; Salami et al. 2013).

\subsection{Wind potential}

Two cases of the Weibull distribution and the hybrid distribution are fitted to the observed wind speed frequency histogram. Fig. 3 shows the wind speed probability density function estimated by different methods and models. The solid line represents the Weibull distribution in which parameters are calculated by the MoMaLiMe. The dash dot line represents the Weibull distribution in which parameters are calculated by the MaLiMe. Finally, the long dash line represents the hybrid density function. It is observed in Fig. 3 that the curve of the Weibull probability density function which use MoMaLiMe match better the histogram.

Fig. 4 shows the wind speed cumulative distribution functions. The goodness of fit of the various fitted distributions to the wind speed data is evaluated using the Quantile - Quantile plots, the Pearson's coefficient of correlation R associated with the Probability Density Function (PDF) plots, the mean speed with its related standard deviation and MSE, the energy density and its relative error.

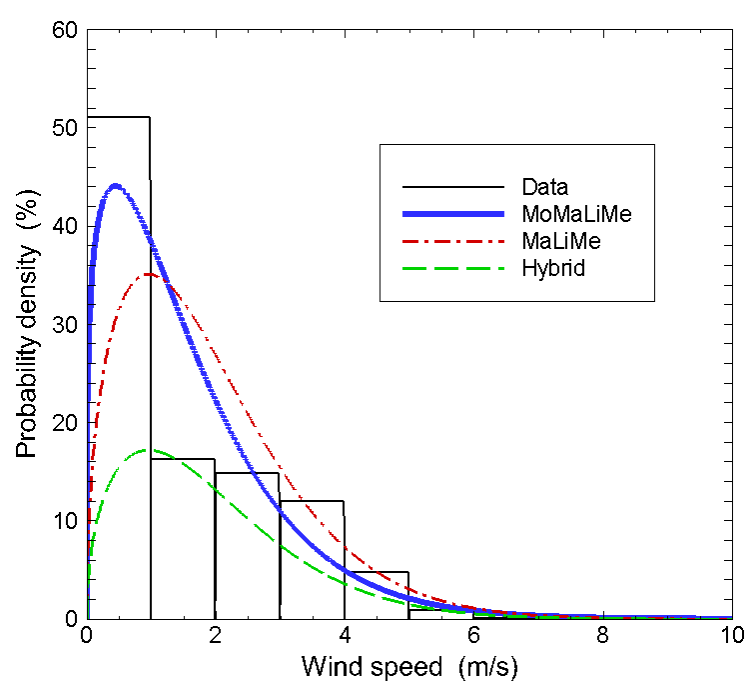

Fig. 3 Wind speed probability density functions

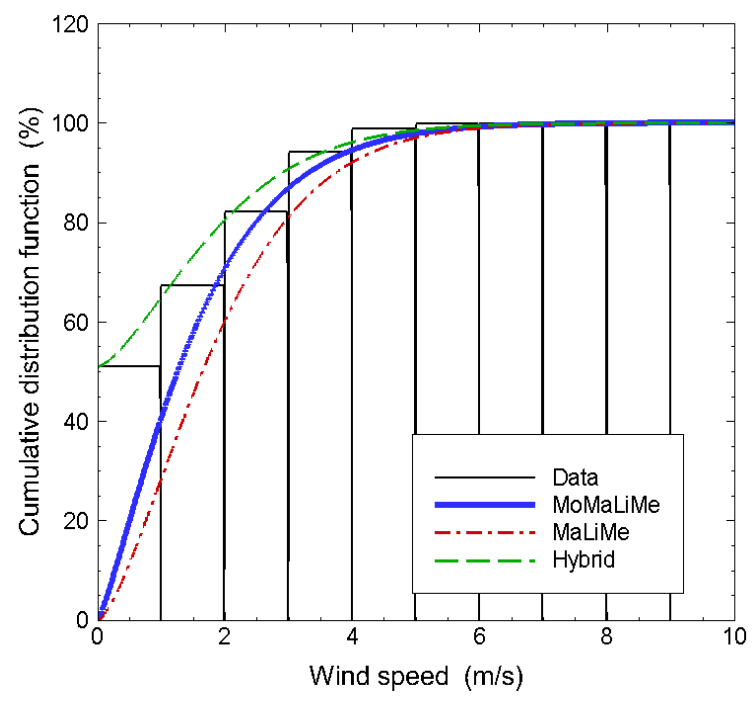

Fig. 4 Wind speed cumulative distribution functions

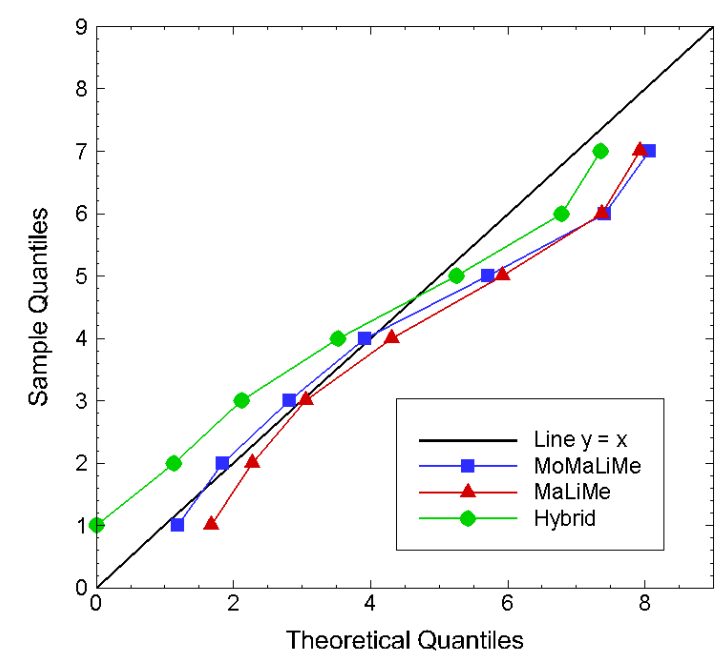

Fig. 5 Quantile-Quantile plot of the Weibull and hybrid distributions 


\subsubsection{Quantile - Quantile (Q-Q) plot}

In statistics, a Q-Q plot is a probability plot, which is a graphical method for comparing two probability distributions by plotting their quantiles against each other (Gibbons \& Chakraborti 2003). From the observed statistical set, one calculates some sample quantiles $x_{i}$. If the statistical set fit well the chosen theoretical distribution, one should have sample quantiles $x_{i}$ equal to quantiles $x_{i}^{*}$ related to the theoretical model. Then, one represent points $\mathrm{M}_{\mathrm{i}}\left(x_{i}{ }^{*}, x_{i}\right)$ with theoretical quantiles on $\mathrm{x}$-axis and sample quantiles on $\mathrm{y}$-axis. If the chosen theoretical distribution is pertinent, fitted points must follow the line $\mathrm{y}=\mathrm{x}$ (Zhang et al. 2013). Theoretical quantiles are calculated by the equation (25).

$x_{i}^{*}=F^{-1}\left(p_{i}\right)$

where:

- $p_{i}$ is the probability related to the sample quantile $x_{i}$

- $\quad F^{-1}$ is the reciprocal function of the cumulative density function.

It is observed that the MoMaLiMe follows the line $\mathrm{y}=$ $\mathrm{x}$ more closely than other distributions, as one can see it in Fig. 5.

\subsubsection{Correlation coefficient of Pearson}

The coefficient of correlation is a measure of the agreement between an estimated distribution and the recorded data (Zhang et al. 2013). The coefficient of correlation $\mathrm{R}$ between the paired PDF data values is evaluated by the following equation (26),

$$
R=\frac{\sum_{i=1}^{n}\left(x_{i}-\bar{x}\right)\left(y_{i}-\bar{y}\right)}{\sqrt{\left(\sum_{i=1}^{n}\left(x_{i}-\bar{x}\right)^{2}\right)\left(\sum_{i=1}^{n}\left(y_{i}-\bar{y}\right)^{2}\right)}}
$$

where:

- $x_{i}$ are the observed data values,

- $y_{i}$ the predicted data values.

The closer the value of $\mathrm{R}$ is to one, the more the fitted distribution agrees with the observed data. Table 1 shows the comparison of the coefficient of correlation for different models. It is observed that the Weibull model with MoMaLiMe has the largest $R$ value. This observation illustrates the strong potential of this approach to provide accurate representations of wind distribution. Regarding the probability density function, the accuracy of fit to the wind speed data of the Weibull distribution using MoMaLiMe is higher than others and this is confirmed by the calculated correlation coefficient.
Table 1

Correlation coefficient of Pearson

\begin{tabular}{lccc}
\hline \multirow{2}{*}{$\begin{array}{c}\text { Distribution } \\
\text { model }\end{array}$} & \multicolumn{2}{c}{ Weibull } & Hybrid \\
\cline { 2 - 3 } & MoMaLiMe & MaLiMe & \\
\hline $\mathrm{R}$ & 0.908101857 & 0.781738520 & 0.781743824 \\
\hline
\end{tabular}

\subsubsection{Mean speed, Standard deviation and MSE}

We applied the previously presented equations to the calculation of the mean speed, the standard deviation and the MSE for each month. The results are presented in table 2 .

It is seen that values of the mean speed obtained by the MoMaLiMe are more closer to those obtained from data than others approaches. Furthermore, most MSE values calculated by the MoMaLiMe are closer to those of data than others MSE values (table 2).

\subsection{Energy density estimation}

\subsubsection{The height is $10 \mathrm{~m}$}

For each month of the collection period, the energy density is calculated and the Results are presented in table 3. Here, the observation is the same as previously. The values of the mean energy density calculated by MoMaLiMe are closer to those obtained from data than those calculated from MaLiMe and hybrid.

\subsubsection{Relative error on energy density estimated}

For a better appreciation of the accuracy of MoMaLiMe, we evaluated the relative errors on the energy density calculated from different models used. Fig. 6 shows the estimated relative errors of hybrid distribution and Weibull distribution with its two cases (MoMaLiMe, MaLiMe). Observation shows that Weibull distribution with parameters which are calculated by the MoMaLiMe performs better than others, the energy density estimations.

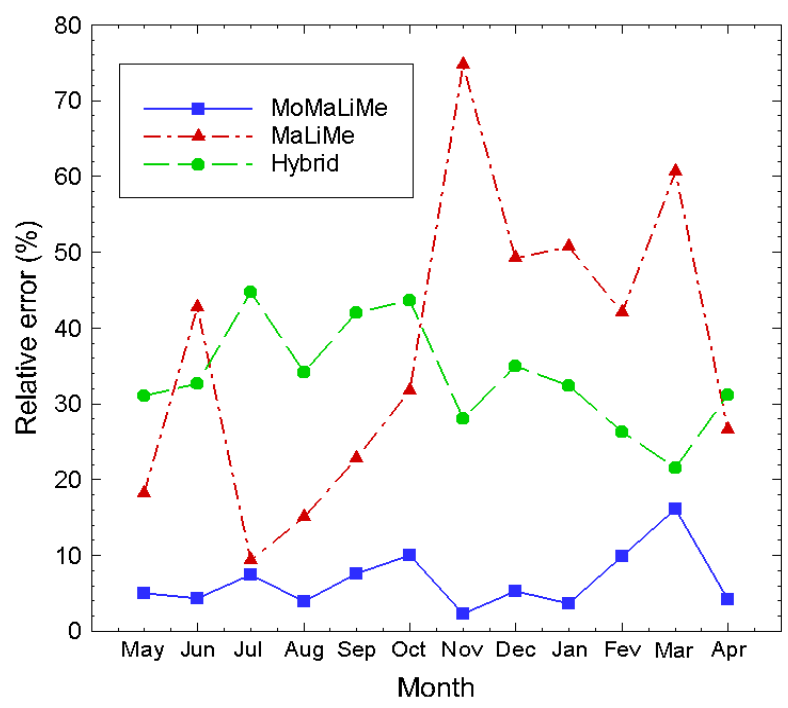

Fig. 6 Relative error on the estimated energy density at $10 \mathrm{~m}$ of height 
Citation: Mouangue, R.M., Kazet, M.Y., Kuitche, A. \& Ndjaka, J.M. (2014) Influence of the Determination Methods of K and C Parameters on the Ability of Weibull Distribution to Suitably Estimate Wind Potential and Electric Energy. Int. Journal of Renewable Energy Development, 3(2), 145-154 doi: 10.14710/ijred.3.2.145-154

P a g e $1 \mathbf{1 5 2}$

Table 2

Monthly results of mean speed, standard deviation and MSE calculated from different approaches and models

\begin{tabular}{|c|c|c|c|c|c|c|c|c|c|c|c|c|}
\hline \multirow[t]{3}{*}{ Months } & \multirow{2}{*}{\multicolumn{3}{|c|}{ Data }} & \multicolumn{6}{|c|}{ Weibull } & \multicolumn{3}{|c|}{ Hybrid } \\
\hline & & & & \multicolumn{3}{|c|}{ MoMaLiMe } & \multicolumn{3}{|c|}{ MaLiMe } & \multirow[b]{2}{*}{$V_{m}{ }^{H}$} & \multirow[b]{2}{*}{$\sigma$} & \multirow[b]{2}{*}{ MSE } \\
\hline & $\bar{V}$ & $\sigma$ & MSE & $V_{m}$ & $\sigma$ & MSE & $V_{m}$ & $\sigma$ & MSE & & & \\
\hline May-11 & 1.7880 & 1.3845 & 0.2130 & 1.7955 & 1.3730 & 0.2094 & 2.0292 & 1.3410 & 0.1998 & 1.1849 & 1.4321 & 0.2563 \\
\hline Jun-11 & 1.4379 & 1.2108 & 0.1832 & 1.4490 & 1.1499 & 0.1652 & 1.8844 & 1.1898 & 0.1769 & 0.8892 & 1.2461 & 0.1941 \\
\hline July-11 & 1.4419 & 1.1851 & 0.1755 & 1.4528 & 1.1205 & 0.1569 & 1.6405 & 1.1308 & 0.1598 & 0.8282 & 1.1482 & 0.1648 \\
\hline Aug-11 & 1.6909 & 1.3071 & 0.2135 & 1.6991 & 1.2865 & 0.2068 & 1.8870 & 1.2614 & 0.2273 & 1.0791 & 1.3348 & 0.2227 \\
\hline Sept-11 & 1.4060 & 1.1912 & 0.1773 & 1.4169 & 1.1194 & 0.1566 & 1.6571 & 1.1821 & 0.1746 & 0.7820 & 1.1594 & 0.1680 \\
\hline Oct-11 & 1.2920 & 1.1093 & 0.1538 & 1.3055 & 1.0291 & 0.1323 & 1.6033 & 1.1067 & 0.1531 & 0.6862 & 1.0741 & 0.1442 \\
\hline Nov-11 & 1.4709 & 1.3214 & 0.2182 & 1.4794 & 1.2633 & 0.1995 & 2.0048 & 1.4039 & 0.2464 & 0.8259 & 1.3365 & 0.2232 \\
\hline Dec-11 & 1.5239 & 1.3264 & 0.2199 & 1.5327 & 1.2868 & 0.2069 & 1.9201 & 1.3557 & 0.2297 & 0.8352 & 1.3063 & 0.2133 \\
\hline Janv-12 & 1.5760 & 1.4072 & 0.2475 & 1.5846 & 1.3565 & 0.2300 & 1.9812 & 1.4577 & 0.2656 & 0.8893 & 1.3874 & 0.2406 \\
\hline Feb-12 & 1.7949 & 1.5303 & 0.2927 & 1.8027 & 1.5159 & 0.2872 & 2.1619 & 1.5638 & 0.3056 & 1.1220 & 1.5612 & 0.3046 \\
\hline Mar-12 & 1.7869 & 1.5246 & 0.2905 & 1.7929 & 1.5323 & 0.2935 & 2.2623 & 1.5883 & 0.3153 & 1.1039 & 1.5845 & 0.3138 \\
\hline Apr-12 & 1.6369 & 1.2908 & 0.2082 & 1.6460 & 1.2677 & 0.2008 & 1.9567 & 1.2409 & 0.2009 & 1.0643 & 1.3370 & 0.2234 \\
\hline
\end{tabular}

Global

\begin{tabular}{lllllllllllll}
1 year & 1.5689 & 1.3305 & 0.2212 & 1.5781 & 1.2840 & 0.2061 & 1.9114 & 1.3298 & 0.2211 & 0.9365 & 1.3343 & 0.2225 \\
\hline
\end{tabular}

Table 3

Monthly results of energy density and Weibull parameters calculated from different approaches and models

\begin{tabular}{|c|c|c|c|c|c|c|c|c|c|c|c|}
\hline \multirow[t]{3}{*}{ Months } & \multirow{3}{*}{$\begin{array}{c}\text { Data } \\
\bar{E}_{D}\end{array}$} & \multicolumn{6}{|c|}{ Weibull } & \multicolumn{4}{|c|}{ Hybrid } \\
\hline & & \multicolumn{3}{|c|}{ MoMaLiMe } & \multicolumn{3}{|c|}{ MaLiMe } & \multirow[b]{2}{*}{$\boldsymbol{k}$} & \multirow[b]{2}{*}{$C$} & \multirow[b]{2}{*}{$F_{O}$} & \multirow[b]{2}{*}{$\boldsymbol{E}_{D}$} \\
\hline & & $\boldsymbol{k}$ & $C$ & $E_{D}$ & $\boldsymbol{k}$ & $C$ & $E_{D}$ & & & & \\
\hline May-11 & 9.4387 & 1.320 & 1.950 & 9.9149 & 1.544 & 2.255 & 11.1553 & 1.544 & 2.255 & 0.416 & 6.5165 \\
\hline June-11 & 5.8483 & 1.269 & 1.561 & 5.5937 & 1.623 & 2.104 & 8.3416 & 1.623 & 2.104 & 0.528 & 3.9361 \\
\hline July-11 & 5.7643 & 1.308 & 1.575 & 5.3375 & 1.475 & 1.813 & 6.3043 & 1.475 & 1.813 & 0.495 & 3.1834 \\
\hline Aug-11 & 7.9364 & 1.334 & 1.849 & 8.2493 & 1.525 & 2.094 & 9.1331 & 1.525 & 2.094 & 0.428 & 5.2239 \\
\hline Sept-11 & 5.6059 & 1.275 & 1.528 & 5.1851 & 1.421 & 1.822 & 6.8828 & 1.421 & 1.822 & 0.528 & 3.2502 \\
\hline Oct-11 & 4.4782 & 1.276 & 1.406 & 4.0318 & 1.473 & 1.772 & 5.8992 & 1.473 & 1.772 & 0.572 & 2.5256 \\
\hline Nov-11 & 6.7628 & 1.175 & 1.564 & 6.9129 & 1.450 & 2.211 & 11.8120 & 1.450 & 2.211 & 0.588 & 4.8686 \\
\hline Dec-11 & 7.0494 & 1.196 & 1.628 & 7.4172 & 1.437 & 2.115 & 10.5215 & 1.437 & 2.115 & 0.565 & 4.5807 \\
\hline Janv-12 & 8.2415 & 1.172 & 1.674 & 8.5389 & 1.375 & 2.167 & 12.4148 & 1.375 & 2.167 & 0.551 & 5.5742 \\
\hline Feb-12 & 11.0278 & 1.194 & 1.914 & 12.1094 & 1.400 & 2.372 & 15.6543 & 1.400 & 2.372 & 0.481 & 8.1321 \\
\hline Mar-12 & 10.6132 & 1.174 & 1.895 & 12.3265 & 1.446 & 2.494 & 17.0455 & 1.446 & 2.494 & 0.512 & 8.3222 \\
\hline Apr-12 & 7.4298 & 1.310 & 1.785 & 7.7419 & 1.615 & 2.184 & 9.3991 & 1.615 & 2.184 & 0.456 & 5.1142 \\
\hline \multicolumn{12}{|l|}{ Global } \\
\hline 1 year & 7.5026 & 1.236 & 1.690 & 7.5932 & 1.460 & 2.110 & 10.1252 & 1.460 & 2.110 & 0.510 & 4.9657 \\
\hline
\end{tabular}


Table 4

Monthly wind characteristics calculated using Weibull distribution with MoMaLiMe

\begin{tabular}{lcccc}
\hline $\begin{array}{c}\text { Monthly } \\
\text { period }\end{array}$ & $\begin{array}{c}\text { Weibull parameter } \\
\text { (MoMaLiMe) }\end{array}$ & $\begin{array}{c}\text { Mean } \\
\text { speed }\end{array}$ & $\begin{array}{c}\text { Energy } \\
\text { density }\end{array}$ \\
\cline { 2 - 3 } & $\boldsymbol{k}$ & $\begin{array}{c}\boldsymbol{C} \\
(\mathbf{m} / \mathbf{s})\end{array}$ & $\begin{array}{c}\overline{\boldsymbol{v}} \\
(\mathbf{m} / \mathbf{s})\end{array}$ & $\begin{array}{c}\boldsymbol{E}_{\boldsymbol{D}} \\
\left(\mathbf{W} / \mathbf{m}^{2}\right)\end{array}$ \\
\hline May-11 & 1.60 & 4.00 & 3.58 & 58.93 \\
Jun-11 & 1.44 & 3.10 & 2.82 & 33.19 \\
Jul-11 & 1.33 & 3.10 & 2.89 & 39.34 \\
Aug-11 & 1.62 & 3.80 & 3.38 & 49.52 \\
Sept-11 & 1.35 & 3.20 & 2.92 & 41.83 \\
Oct-11 & 1.21 & 2.90 & 2.75 & 40.80 \\
Nov-11 & 1.28 & 4.50 & 4.15 & 130.49 \\
Dec-11 & 1.37 & 4.80 & 4.43 & 135.97 \\
Jan-12 & 1.36 & 4.70 & 4.30 & 129.76 \\
Fev-12 & 1.31 & 5.20 & 4.84 & 188.01 \\
Mar-12 & 1.40 & 5.80 & 5.28 & 225.55 \\
Apr-12 & 1.54 & 3.60 & 3.26 & 45.84 \\
\hline
\end{tabular}

\subsubsection{Extrapolation at $120 \mathrm{~m}$}

By applying equation (21) on the set of measured data taken at the measurement height, one obtains these synthetic sets of data at the desired height of 120 m (Table 4).

\subsection{Electric output energy}

The monthly and annual energy productions are calculated using equation (15). The time period of the data collection is one year that is to say 8784 hours. The power curve of the wind turbine generator used is that of Vestas V82 (Fig. 1) which has the following characteristics: cut-in wind speed ( $3 \mathrm{~m} / \mathrm{s})$, cut-out wind speed $(20 \mathrm{~m} / \mathrm{s})$ and a rated power of $1650 \mathrm{~kW}$.

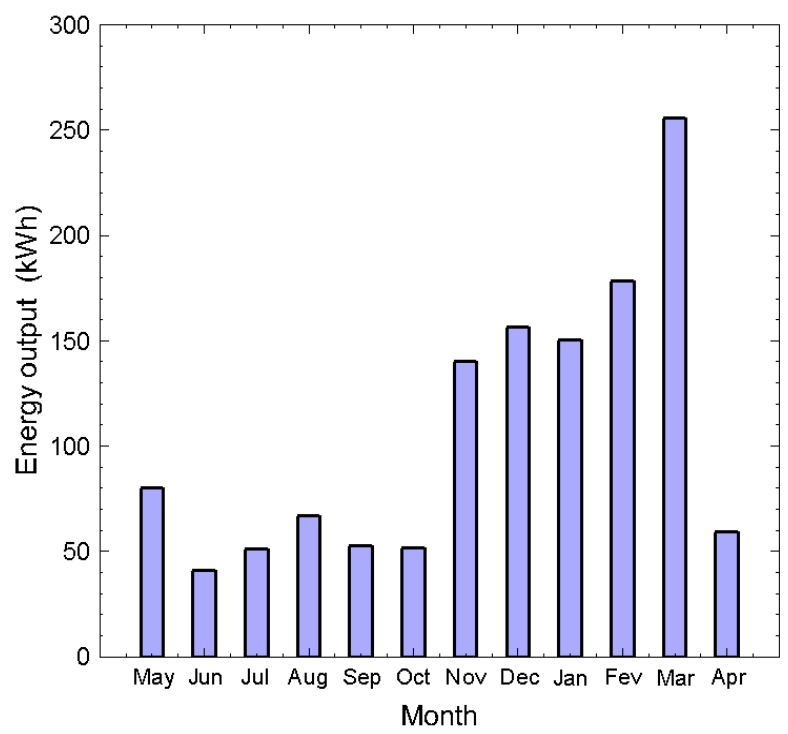

Fig. 7 The monthly Electric output energy calculated using the Weibull distribution and the wind power curve of Vestas V82 wind turbine generator
Table 5

Global wind characteristics calculated using Weibull distribution with MoMaLiMe

\begin{tabular}{|c|c|c|c|c|c|}
\hline \multirow{2}{*}{$\begin{array}{c}\text { Period } \\
\text { of } 12 \\
\text { months }\end{array}$} & \multicolumn{2}{|c|}{$\begin{array}{c}\text { Weibull parameter } \\
\text { (MoMaLiMe) }\end{array}$} & \multirow{2}{*}{$\begin{array}{c}\text { Mean } \\
\text { speed } \\
\bar{v} \\
(\mathrm{~m} / \mathrm{s}) \\
\end{array}$} & \multirow{2}{*}{$\begin{array}{c}\text { Energy } \\
\text { density } \\
E_{D} \\
\left(\mathrm{~W} / \mathrm{m}^{2}\right)\end{array}$} & \multirow{2}{*}{$\begin{array}{c}\text { Output } \\
\text { energy } \\
E_{E L} \\
\text { (MWh) }\end{array}$} \\
\hline & $\begin{array}{l}\boldsymbol{k} \\
- \\
\end{array}$ & $\begin{array}{c}C \\
(\mathrm{~m} / \mathrm{s}) \\
\end{array}$ & & & \\
\hline $\begin{array}{l}05 / 2011 \\
\text { to } \\
04 / 2012\end{array}$ & 1.26 & 4.00 & 3.75 & 95.85 & 1332.5 \\
\hline
\end{tabular}

Fig. 7 shows the monthly energy outputs for the airport site. The most energy contribution is made in March with 255.7 MWh, while the least energy contribution is observed to be $41.1 \mathrm{MWh}$ in June. While using the synthetic set of data from $120 \mathrm{~m}$ of height, we obtained some global wind characteristics. Table 5 presents the Weibull parameters, the mean speed, the energy density and the annual energy production for the whole data used.

From the whole of the results, It is observed that quantiles calculated from the Weibull distribution in which parameters are determined by the MoMaLiMe follows the line $y=x$ more closely than other distributions. Furthermore, values of the mean speed and energy density calculated from the same distribution are very close to those obtained from data. This is not the case of the MaLiMe and the hybrid distribution. Low values of MSE and relative error obtained by using MoMaLiMe suggests that the proposed approach could be more usefull for the wind energy assessment of our site than the Weibull distribution in which parameters are determined by MaLiMe or than the Hybrid distribution.

For the particular site of Ngaoundere airport, it could be concluded that the wind turbine generator doesn't works for at least a half of the time because of higher frequency of calm. Analysis of the observed wind speed distribution for this specific site proves that fact.

According to whether one uses the MoMaLiMe or the MaLiMe, It thus appears in an obvious way that the determination method of Weibull parameters has an influence on the relevance of this distribution.

The calculation principle of $\mathrm{k}$ and $\mathrm{C}$ parameters by using MaLiMe rely on a speed logarithmic calculation. However, $23 \%$ of the velocity measurements of the site are null and of this fact are not taken into account during the calculation of the parameters what has certainly an influence on the awaited result.

\section{Conclusion}

Our study was to estimate and characterize the observed wind potential and to provide the electric output energy of the site of Ngaoundere by using the Weibull distribution in which parameters are determined by the modified maximum likelihood method because of the calm wind observed. The maximum likelihood method and the hybrid 
distribution were also used to compare them to our approach.

Taking the results obtained into account, one can retain at the end of this study the following:

- The maximum likelihood method, which is one of the most used determination method of the Weibull parameters, gives results which are not very satisfactory taking data into consideration. That could be due to the important rate of calm observed in measurements of the site.

- Although the hybrid distribution was proposed by Salami et al. (2013) as the best model that fits the frequency histogram of wind speed and which estimate with precision the amounts of the wind energy, it seems to be not quite satisfactory in the case of the site of Ngaoundere.

- The determination methods of Weibull parameters affect the accuracy of this distribution to model the wind potential of a site.

The modified maximum likelihood method proposed by Seguro and Lambert in 2000 which is recommended for use with wind data in frequency distribution format, is one of the best methods which can be used to determinate Weibull parameters for sites which have important frequency of calm. By using this method, the Weibull distribution appear to be fine for the modeling of the wind potential and for the wind energy assessment, particularly for sites having nonzero probability of calm.

\section{Acknowledgements}

Authors would like to thank the ASECNA weather service of Ngaoundere to have provided the meteorological data used in this work.

\section{References}

ASECNA (2012) Archives data of the weather station of Ngaoundere. Bataineh, K.M. \& Dalalah, D. (2013) Assessment of wind energy po tential for selected areas in Jordan. Renewable Energy, 59, 75-81.

Boudia, S.M., Benmansour, A., Ghellai, N., Benmedjahed, M. \& Hellal, M.A.T. (2013). Temporal assessment of wind energy resource at four locations in Algerian Sahara. Energy Conversion and Management, 76, 654-664.

Carta, J.A., Ramírez, P. \& Velázquez, S. (2008) Influence of the level of fit of a density probability function to wind-speed data on the WECS mean power output estimation. Energy Conversion and Management, 49, 2647-2655.

Đurišić, Ž. \& Mikulović, J. (2012) A model for vertical wind speed data extrapolation for improving wind resource assessment using WAsP. Renewable Energy, 41, 407-411.
Gibbons, J., Chakraborti, S. (2003) Nonparametric statistical inference. CRC Press.

Jamil, M., Parsa, S. \& Majidi, M. (1995) Wind power statistics and an evaluation of wind energy density. Renewable Energy, 6, No. 5-6, 623-628.

Kaldellis, J.K. (2008) Maximum wind potential exploitation in autonomous electrical networks on the basis of stochastic analysis. Journal of Wind Engineering and Industrial Aerodynamics, 96, $1412-1424$

Kazet, M., Mouangue, R., Kuitche, A., Ndjaka, J.M. \& Takam, S. (2013) Modélisation et simulation numérique des données du vent en vue d'une prédiction de l'énergie électrique d'origine éolienne : cas d'un site de la ville de Ngaoundere au Cameroun. Revue des Energies Renouvelables, 16(3), 527 - 538.

Lackner, M.A., Rogers, A.L., Manwell, J.F. \& McGowan, J.G. (2010) A new method for improved hub height mean wind speed estimates using short-term hub height data. Renewable Energy, 35, 23402347.

Li, M. \& Li, X. (2005) MEP-type distribution function: a better alternative to Weibull function for wind speed distributions. Renewable Energy, 30, 1221-1240.

Morales, L., Lang, F. \& Mattar, C. (2012) Mesoscale wind speed simulation using CALMET model and reanalysis information: An application to wind potential. Renewable Energy, 48, 57-71.

Omer, A.M. (2008) On the wind energy resources of Sudan. Renewable and Sustainable Energy Reviews, 12, 2117-2139.

Rahman, M.M., Mostafiz, S.B., Paatero, J.V. \& Lahdelma, R. (2014) Extension of energy crops on surplus agricultural lands: A potentially viable option in developing countries while fossil fuel reserves are diminishing. Renewable and Sustainable Energy Reviews, 29, 108-119.

Ramírez, P. \& Carta, J.A. (2005) Influence of the data sampling interval in the estimation of the parameters of the Weibull wind speed probability density distribution: a case study. Energy Conversion and Management, 46, 2419-2438.

Safari, B. \& Gasore, J. (2010) A statistical investigation of wind characteristics and wind energy potential based on the Weibull and Rayleigh models in Rwanda. Renewable Energy, 35, 28742880.

Salami, A.A., Ajavon, A.S.A., Kodjo, M.K. \& Bedja, K.S. (2013) Contribution to improving the modeling of wind and evaluation of the wind potential of the site of Lome: Problems of taking into account the frequency of calm winds. Renewable Energy, 50, 449455.

Sathyajith, M. (2006) Wind Energy Fundamentals, Resource Analysis and Economics, pp. 68-83. Springer-Verlag Berlin Heidelberg.

Sathyajith, M. \& Geeta, S.P. (2011) Advances in Wind Energy Conversion Technology, pp. 74-80. Springer-Verlag Berlin Heidelberg.

Seguro, J.V. \& Lambert, T.W. (2000) Modern estimation of the parameters of the Weibull wind speed distribution for wind energy analysis. Journal of Wind Engineering and Industrial Aerodynamics, 85, 75-84.

Takle, E.S. \& Brown, J.M. (1978) Note on the Use of Weibull Statistics to Characterize Wind-Speed Data. Journal of Applied Meteorology, 17, 556-559.

Troen, I. \& Petersen, E.L. (1989) European wind atlas. 1st ed. Denmark: Risø National Laboratory.

Vestas technology documentation (2005) General specification of V821.65 MW. http://www.vestas.com/Files/Filer/EN/Brochures/Pro ductBrochureV821 65 UK.pdf. Accessed on 12 December 2013.

Zhang, J., Chowdhurya, S., Messac, A. \& Castillo, L. (2013) A Multivariate and Multimodal Wind Distribution model. Renewable Energy, 51, 436-447. 